\title{
Exploration of New Electroacupuncture Needle Material
}

\author{
Sanghun Lee, ${ }^{1}$ Gwang-Ho Choi, ${ }^{1}$ Chang Hoon Lee, ${ }^{2}$ Yu Kyoung Kim, ${ }^{2}$ Saebhom Lee, ${ }^{1}$ \\ Sungjin Cho, ${ }^{1}$ Sunhee Yeon, ${ }^{1}$ Sun-Mi Choi, ${ }^{1}$ and Yeon-Hee Ryu ${ }^{1}$ \\ ${ }^{1}$ Acupuncture, Moxibustion \& Meridian Research Center, Korea Institute of Oriental Medicine, Daejeon 305-811, Republic of Korea \\ ${ }^{2}$ Technical Research Center, Dong Bang Acupuncture, Inc., Boryeong 355-851, Republic of Korea
}

Correspondence should be addressed to Yeon-Hee Ryu, yhryu@kiom.re.kr

Received 25 November 2011; Revised 24 January 2012; Accepted 24 January 2012

Academic Editor: Xinyan Gao

Copyright (c) 2012 Sanghun Lee et al. This is an open access article distributed under the Creative Commons Attribution License, which permits unrestricted use, distribution, and reproduction in any medium, provided the original work is properly cited.

\begin{abstract}
Background. Electro Acupuncture (EA) uses the acupuncture needle as an electrode to apply low-frequency stimulation. For its safe operation, it is essential to prevent any corrosion of the acupuncture needle. Objective. The aim of this study is to find an available material and determine the possibility of producing a standard EA needle that is biocompatible. Methods. Biocompatibility was tested by an MTT assay and cytotoxicity testing. Corrosion was observed with a scanning electron microscope (SEM) after $0.5 \mathrm{~mA}$, $60 \mathrm{~min}$ stimulation. The straightness was measured using a gap length of $100 \mathrm{~mm}$, and tensile testing was performed by imposing a maximum tensile load. Results. Phosphor bronze, Ni coated SS304, were deemed inappropriate materials because of mild-tomoderate cytotoxicity and corrosion. Ti-6Al-4V and SS316 showed no cytotoxicity or corrosion. Ti-6Al-4V has a 70 times higher cost and 2.5 times lower conductivity than SS316. The results of both straightness and tensile testing confirmed that SS316 can be manufactured as a standard product. Conclusion. As a result, we confirmed that SS316 can be used a new EA electrode material. We hope that a further study of the maximum capacity of low-frequency stimulation using an SS316 for safe operation.
\end{abstract}

\section{Introduction}

Electroacupuncture is a combination of acupuncture from oriental medicine and low-frequency $(1-1,000 \mathrm{~Hz})$ stimulation, which is a type of physical therapy used in western medicine. Low-frequency stimulation was first proposed in 1816 by Louis Berlioz of France, who suggested that electrical stimulation combined with acupuncture treatment could enhance the effectiveness of the treatment. Later, in 1825, Sarlandiere used this technique to treat gout and neurological diseases, and he published a report in which he referred to the technique as "galvanopuncture," from which the term electroacupuncture is derived [1]. Since that time, electroacupuncture has been used by many researchers who have noted a variety of effects, such as an increased pain threshold [2], increased gastrointestinal movement [3], and weight loss [4], and as a result, there has been an increase in the technique's application in clinics worldwide. However, due to the electrical properties of the current generated by a low-frequency stimulator, electro acupuncture poses safety problems that are distinct from those of traditional acupuncture. Lytle et al. [5] have identified a number of elements related to the safety of the electrical properties of the current generated by a low-frequency stimulator, such as voltage, waveforms, and the pulse frequency and width. Cummings [6] has also focused upon a number of safety elements, such as the possibility of a change in needle depth during electrical stimulation, risk of damage to internal organs due to muscle contraction and needle vibration, needle corrosion due to excessive charging, the caution required when treating areas at risk of shock, such as the area around carotid artery, as well as concerns regarding the interaction of the instrument with patients wearing pacemakers. In particular, Park [7] and Jin [8] studied several electro acupuncture devices and reported that there was no significant difference in corrosion, hardness, or cytotoxicity on the needle surface and tip before and after its operation, while Hwang [9] reported that corrosion was observed in the interface between skin and air when the current is above $0.05 \mathrm{~mA}$ and that this corrosion increased with an 
TABLE 1: Allocation of experimental group and control group.

\begin{tabular}{ccc}
\hline No. & Wire & Assignment \\
\hline$(1)$ & Ti-6-Al-4V $0.20 \mathrm{~mm}$ & Experimental group \\
$(2)$ & Phosphor bronze $0.25 \mathrm{~mm}$ & Experimental group \\
$(3)$ & SS $304 \mathrm{Ni} 20 \mathrm{~mm}$ & Experimental group \\
$(4)$ & SS $304 \mathrm{Ni} 25 \mathrm{~mm}$ & Experimental group \\
$(5)$ & SS $304 \mathrm{Ni} 30 \mathrm{~mm}$ & Experimental group \\
$(6)$ & SS 3160.20 & Experimental group \\
$(7)$ & SS 3160.25 & Experimental group \\
$(8)$ & SS 3160.30 & Experimental group \\
$(9)$ & DMEM/F-12 & Control group \\
\hline
\end{tabular}

TABLE 2: Chemical composition of Hank's solution.

\begin{tabular}{lc}
\hline Component & Concentration $\left(\mathrm{mol} \mathrm{dm}^{-3}\right)$ \\
\hline $\mathrm{NaCl}$ & 137.0 \\
$\mathrm{KCl}$ & 5.4 \\
$\mathrm{Na}_{2} \mathrm{HPO}_{4}$ & 0.25 \\
$\mathrm{KH}_{2} \mathrm{PO}_{4}$ & 0.44 \\
$\mathrm{CaCl}_{2}$ & 1.3 \\
$\mathrm{MgSO}_{4}$ & 1.0 \\
$\mathrm{NaHCO}_{3}$ & 4.2 \\
\hline
\end{tabular}

increase in time or in the applied current. Of the austenitic stainless steels, SS 304 is reported to be most vulnerable to corrosion [10]. It becomes vulnerable to corrosion due to sensitization from thermal treatment, as $\mathrm{Cr}$ is extracted at $400 \sim 800^{\circ} \mathrm{C}$, and the Cr-exhausted region causes corrosion [11]. In the investigation of the corrosion safety of SS 304 ear-acupuncture needles, the authors have confirmed that defective processing of the needle point and surface leads to more severe corrosion [12], a finding that is considered applicable to needles that undergo a similar manufacturing process. In the present study, 4 materials -2 materials with higher conductivity and 2 materials with a higher safety than current material-were tested for the possibility of being used as new material for an electroacupuncture needle. The most appropriate material was selected, and its specifications were evaluated to replace the current new acupuncture needles with a new material.

\section{Materials and Methods}

2.1. Experimental Materials. Among the metal wires that are commercially available, we selected phosphor bronze (hereafter referred to as PB) and Ni-coated SS 304 (hereafter referred to as SS $304 \mathrm{Ni}$ ), which both have superior electrical conductivity as compared to SS 304, which is currently used for electro acupuncture, along with titanium alloy (Ti6-Al-4V) and SS 316, which have relatively low electrical conductivity but were expected to demonstrate superior stability. Due to the circumstances involved in purchasing, a thickness of $0.25 \mathrm{~mm}$ was used for $\mathrm{PB}$ and $0.2 \mathrm{~mm}$ for Ti6-Al- $4 \mathrm{~V}$, and thicknesses of $0.2,0.25$, and $0.3 \mathrm{~mm}$ were used for SS $304 \mathrm{Ni}$ and SS 316. All materials were purchased from a company (KOS, Korea) specializing in metal wire.

\subsection{Experimental Methods}

2.2.1. Biocompatibility. MTT (3-(4, 5-dimethyl-2-thiazolyl)2,5 -diphenyl-2H-tetrazolium bromide) assay and cytotoxicity testing were performed in order to assess the biocompatibility of the experimental material. The procedure for each experiment conducted was as follows.

\section{(A) MTT Assay}

(a) Assay Standards and Methods. The cytotoxicity test of ISO 10993-5 for assessment of the cytotoxic potential of a test element (medical device) after direct contact was used as the assay standard.

The procedure composed with cell seeding, contact of the test element, incubation for more than 24 hours, preparation of the coloring solution of revelation, revelation of cytotoxicity, reading.

(b) Extraction Condition. The wires were segmented into $10 \mathrm{~mm}$ sections, and 40 sections were added to $3 \mathrm{~mL}$ of Dulbecco's Modified Eagle's Medium: nutrient mixture F-12 (DMEM/F-12, GIBCO). Extraction was performed at $37^{\circ} \mathrm{C}$ for 48 hours. The assignment of experimental and control groups was as follows (Table 1).

\section{(c) Experimental Method and Evaluation Standards}

(1) Experimental Methods. Mouse osteoblast (MC3T3 cell) was cultured for 24 hours with DMEM/F-12 (5\% FBS, penicillin-streptomycin added). It was inspected for contamination before use. Media of sufficiently grown cells were removed, and media extracts of the experimental group and the control group were cultured separately for 24 hours. The media were then added to a plate with formazan crystal. After the formazan had dissolved, a Dymatech MRX ELISA microplate reader (Dynatech laboratories, Chantilly, VA, USA) was used to measure the absorbance at $540 \mathrm{~nm}$. The average of 3 measurements was used to calculate the percentage of cell solubility. The result of the control group was used as the negative control.

\section{(B) Stain Test}

(a) Experimental Method and Evaluation Standard. The conditions for extraction and cell culture were performed as in an MTT assay. The cultured cells were stained with $0.3 \%$ crystal violet, and a stereoscopic microscope (Leica microsystem DE/EZ4) was used to compare their viability.

\subsubsection{Corrosion Stability}

(A) Corrosion Condition. We prepared $5 \mathrm{~cm}$ of wire for each type. In order to consider body fluid conditions, $1 \mathrm{~cm}$ of each wire was dipped separately into $50 \mathrm{~mL}$ of Hank's solution (Table 2), which is a simulated body fluid, and current was applied at $0.5 \mathrm{~mA}$ for 60 minutes as a continuous wave, step response, $1 \mathrm{~ms}$ duration, and single-phase current. Current 


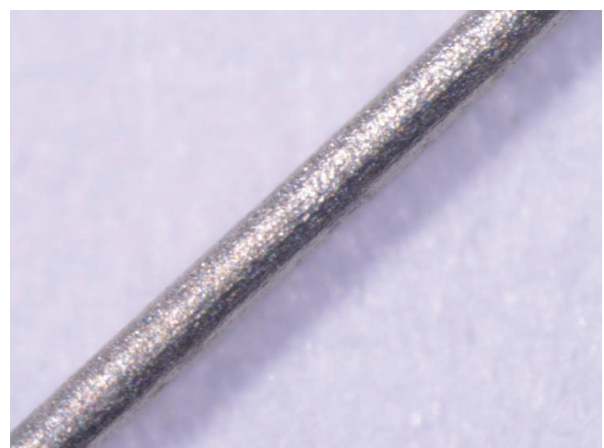

(a1)

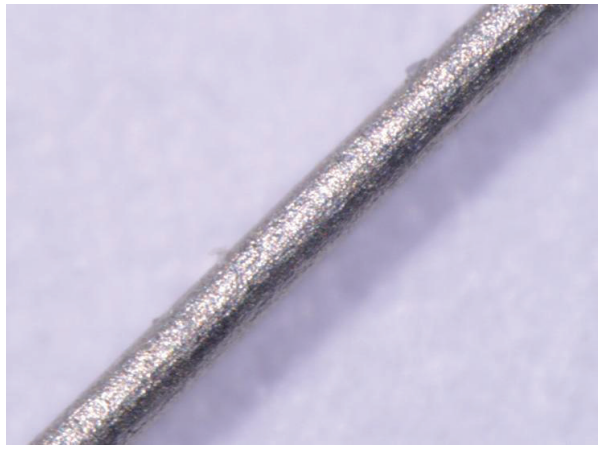

(b1)

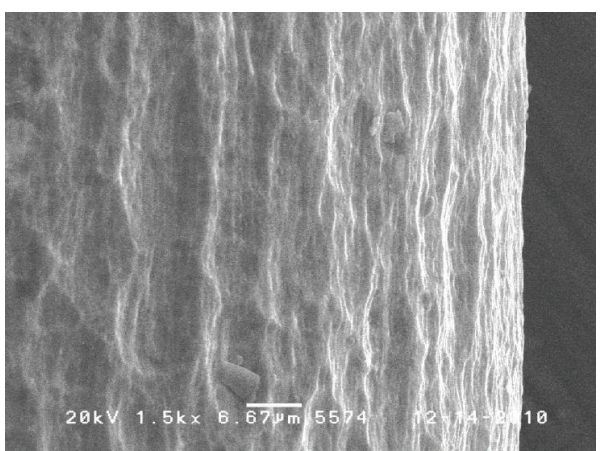

(a2)

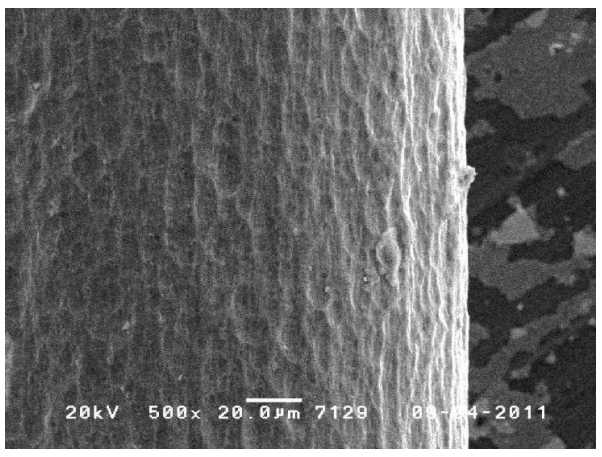

(b2)

FIgure 1: Corrosion test of Ti-6Al-4V: no corrosion was identified on the thickness of $0.20 \mathrm{~mm}$ (B is the control).

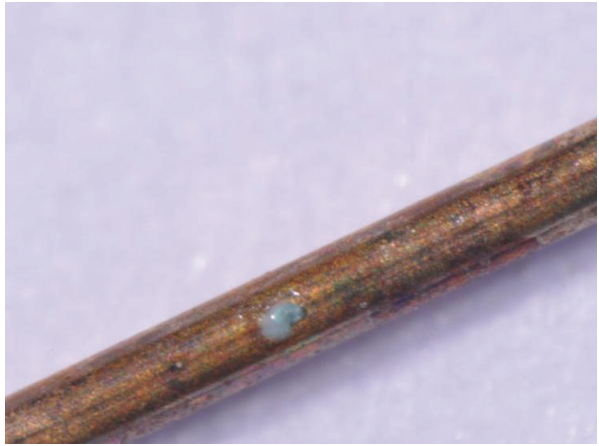

(a1)

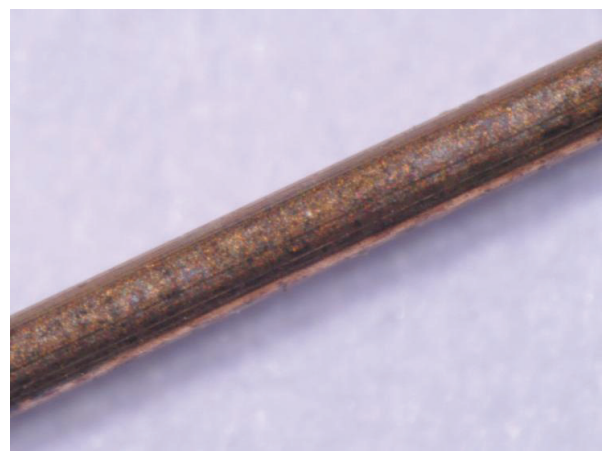

(b1)

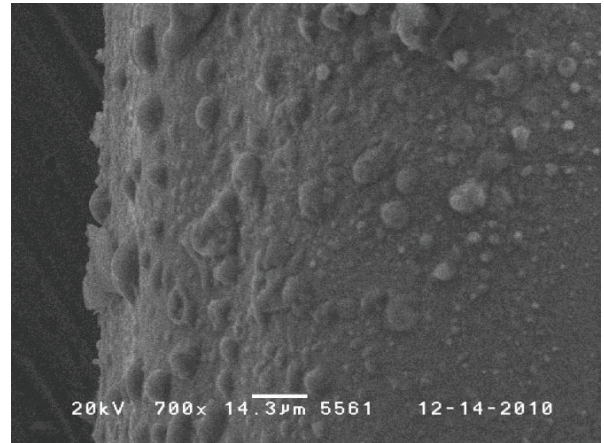

(a2)

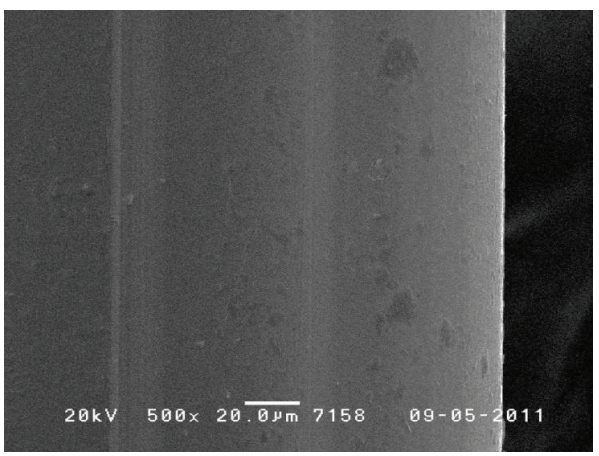

(b2)

FIgURE 2: Corrosion test of PB: corrosion was identified on the thickness of $0.25 \mathrm{~mm}$ (B is the control). 


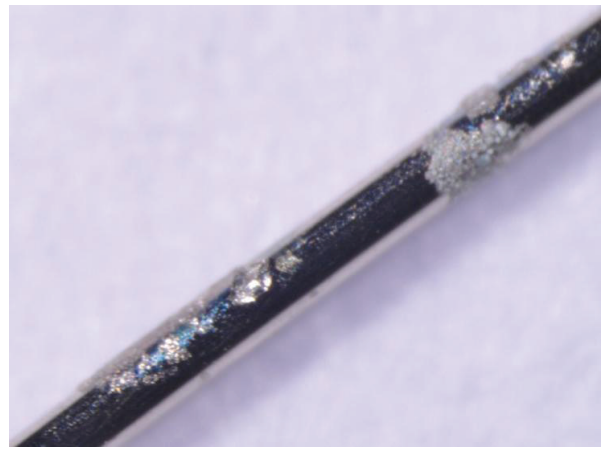

(a1)

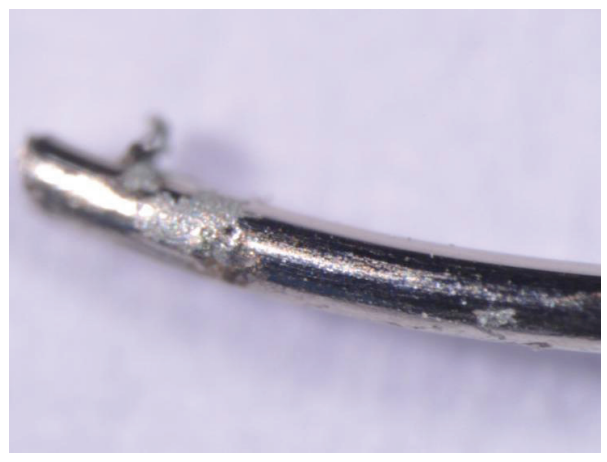

(b1)

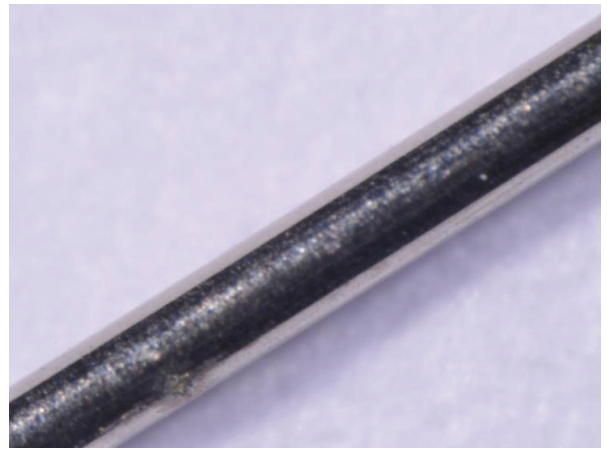

(c1)

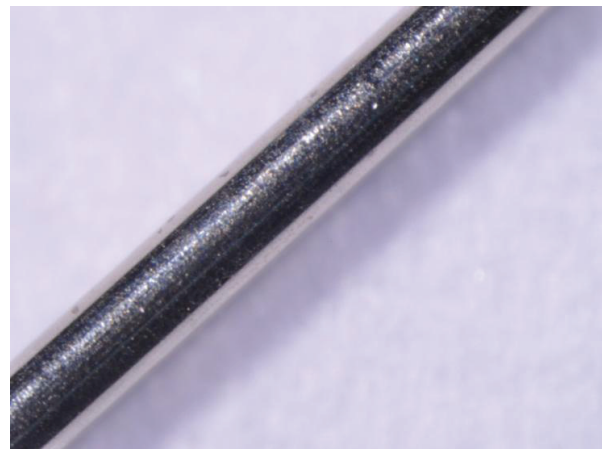

(d1)

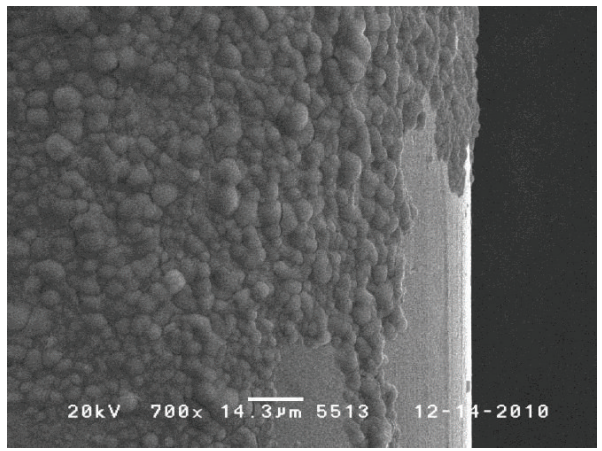

(a2)

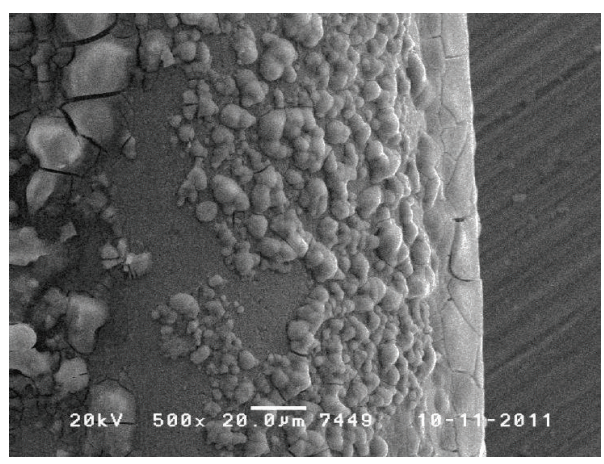

(b2)

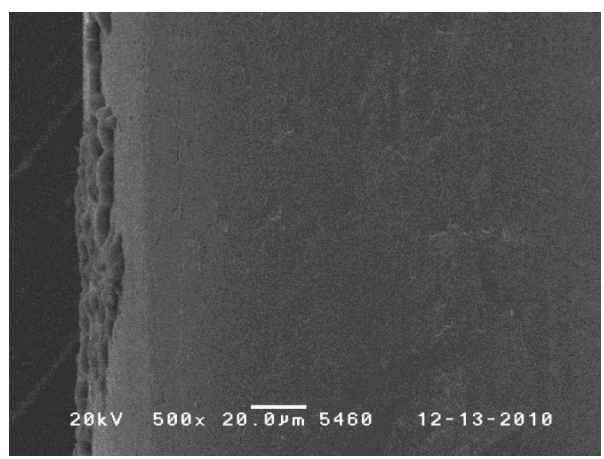

$(\mathrm{c} 2)$
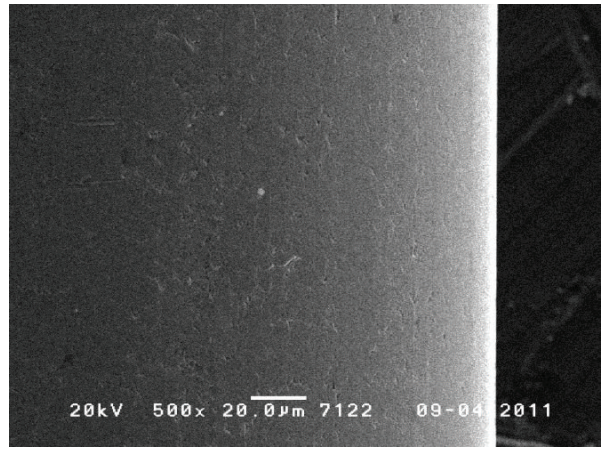

(d2)

Figure 3: Corrosion test of STS $304 \mathrm{Ni}$ : corrosion was identified on all thicknesses (A: $0.20 \mathrm{~mm}, \mathrm{~B}: 0.25 \mathrm{~mm}, \mathrm{C}: 0.30 \mathrm{~mm}, \mathrm{D}$ : control). 


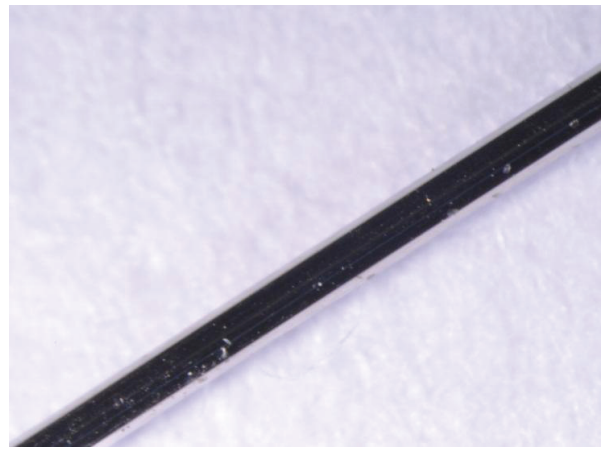

(a1)

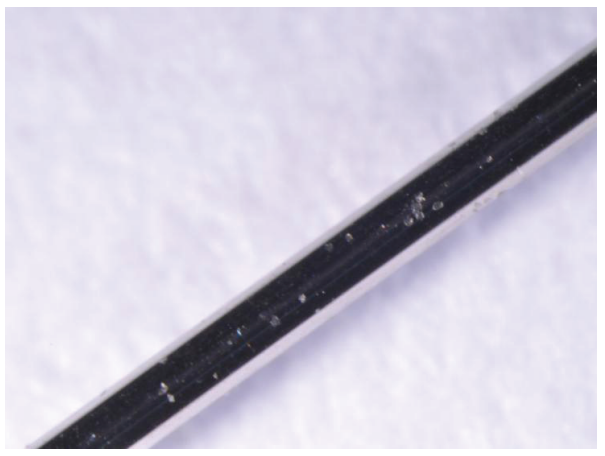

(b1)

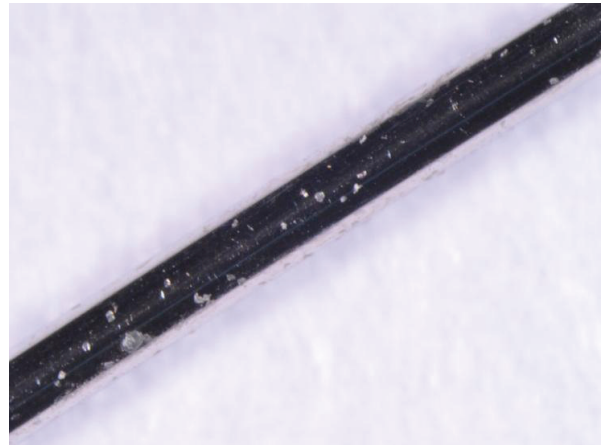

(c1)

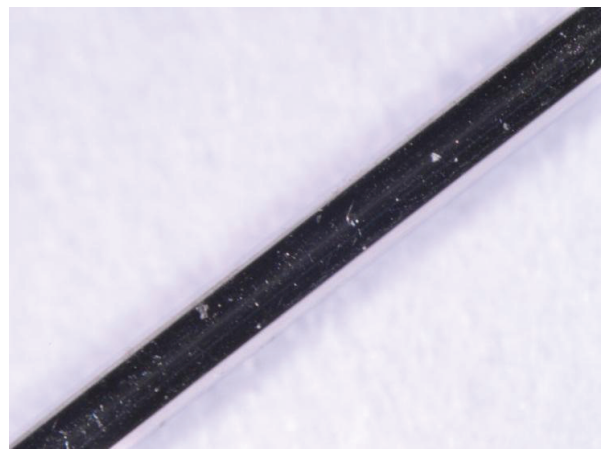

$(\mathrm{d} 1)$

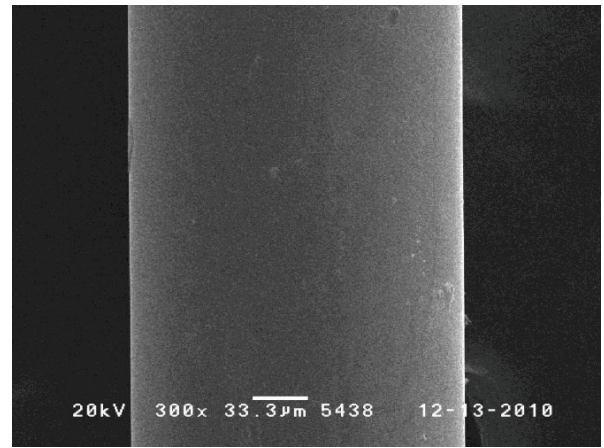

(a2)

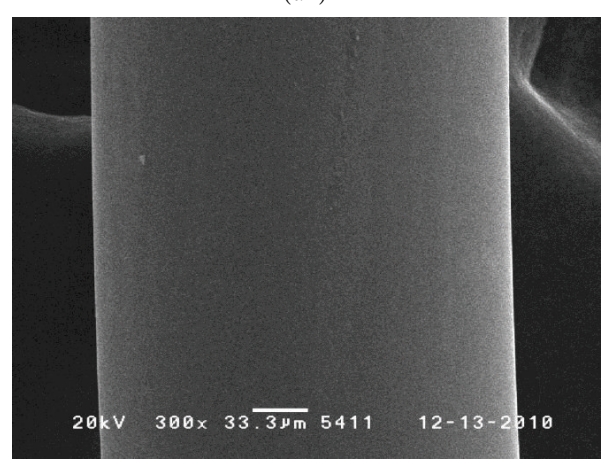

(b2)

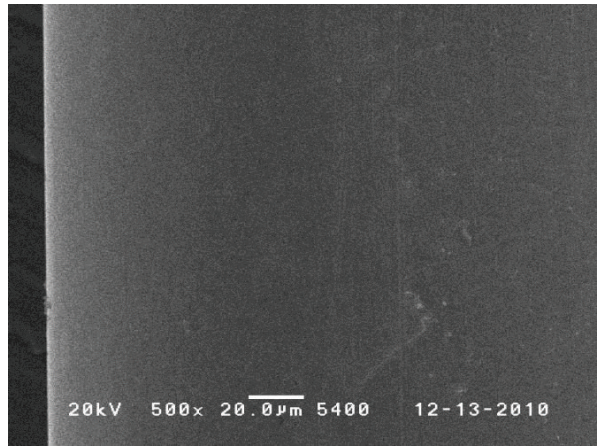

(c2)

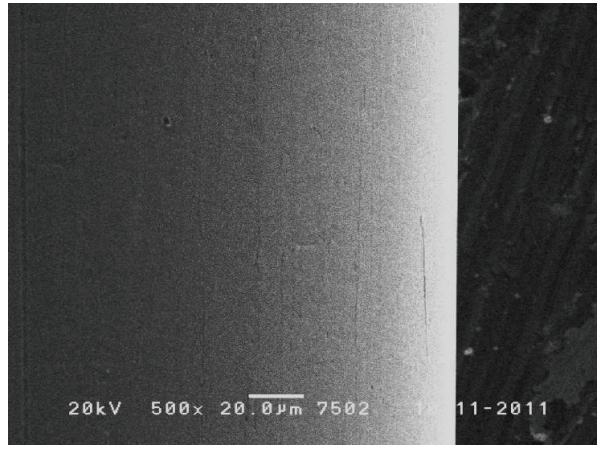

$(\mathrm{d} 2)$

Figure 4: Corrosion test of STS 316: no corrosion was identified on any of the thicknesses (A: 0.20 mm, B: $0.25 \mathrm{~mm}, \mathrm{C}: 0.30 \mathrm{~mm}, \mathrm{D}: \mathrm{control}$ ). 


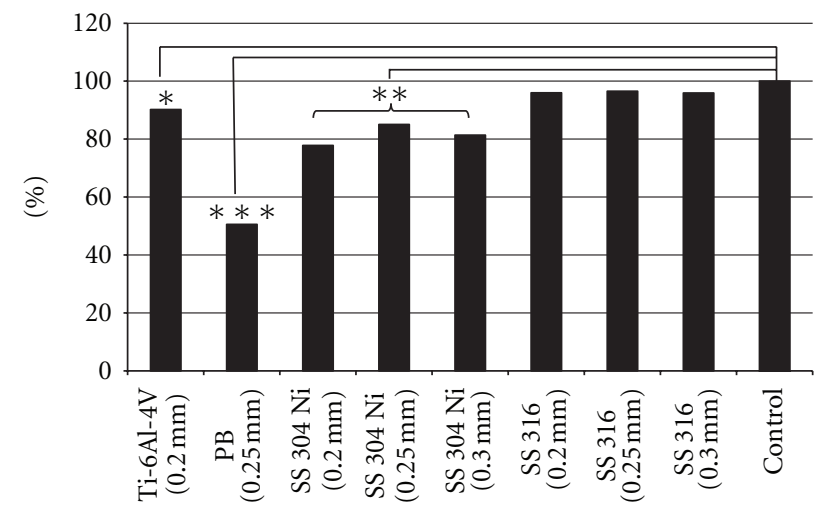

Figure 5: MTT assay result $\left({ }^{*}: P<0.05,{ }^{* *}: P<0.01,{ }^{* * *}: P<0.001\right.$ versus control group).

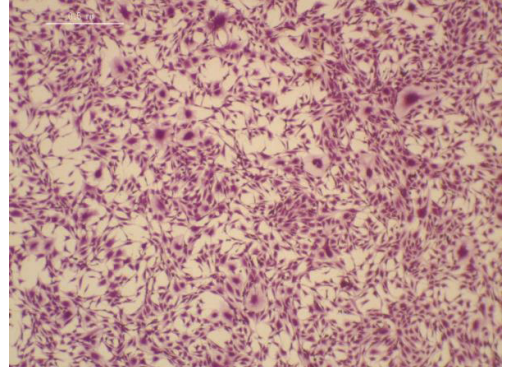

(a)

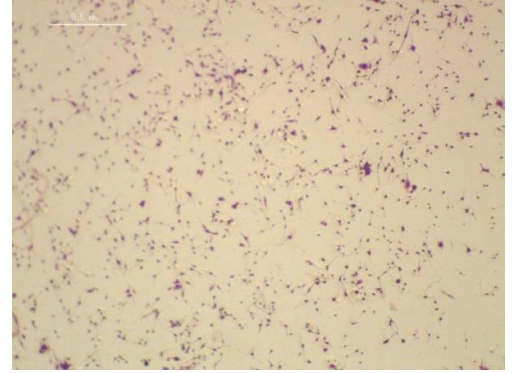

(d1)

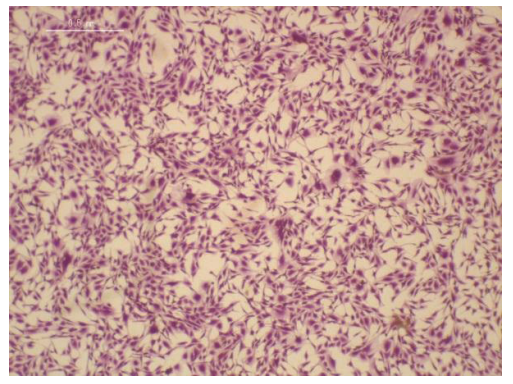

(e1)

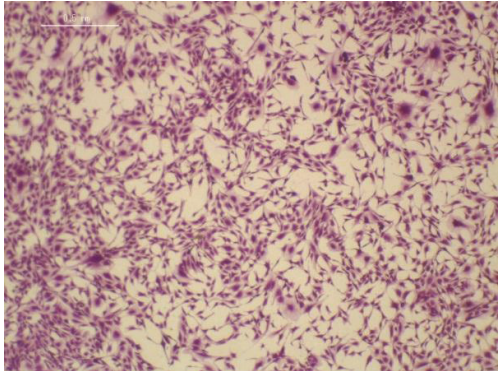

(b)

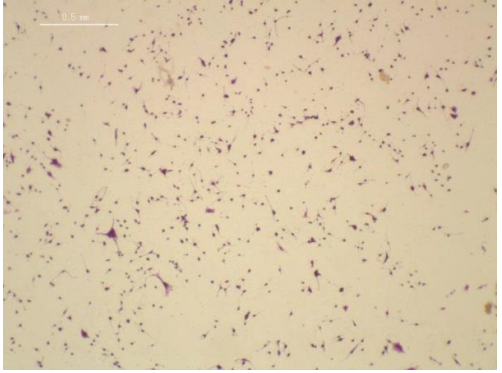

(d2)

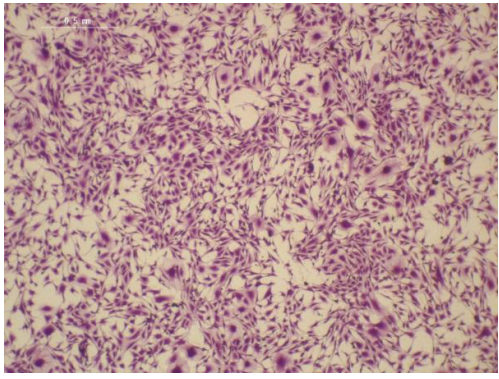

(e2)

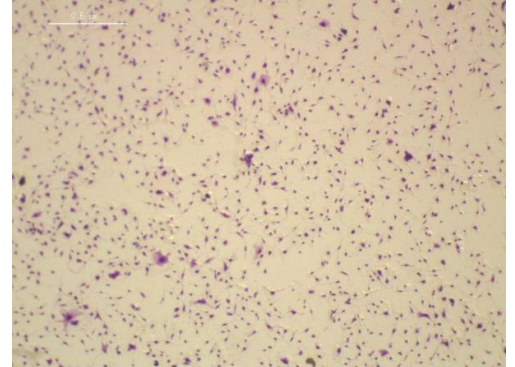

(c)

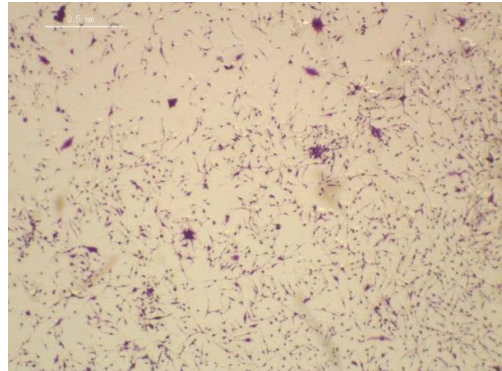

(d3)

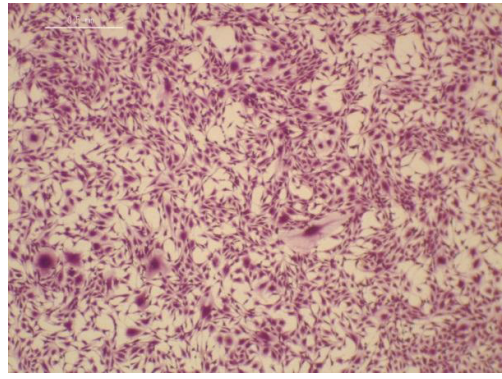

(e3)

FIgure 6: Stain test of each material. B (Ti-6Al-4V) and E (SS 316) show higher rate of survival, while (c) (PB) and (d) (SS 304 Ni) show a lower rate ((a) is the control).

was supplied by a S88 stimulator (GRASS; USA: 0.01 $0.5 \mathrm{~mA})$.

(B) Measurement of Corrosion. A stereoscopic microscope (SMZ 1500, Nikon, Japan) and scanning electron microscope (SEM) were used to observe corrosion. The stereoscopic microscope was used to observe changes in color and shape, and SEM was used to observe surface changes due to corrosion.

2.3. Evaluation of Tensile Strength and Straightness. Wires selected for corrosion stability and biocompatibility were 
TABLE 3: Comparison of cost, conductivity, and tensile strength of wire material (1st of July, 2010).

\begin{tabular}{|c|c|c|c|c|c|}
\hline Material & $\begin{array}{l}\text { Diameter } \\
(\mathrm{mm})\end{array}$ & Material & $\begin{array}{l}\text { Tensile strength } \\
\quad\left(\mathrm{N} / \mathrm{mm}^{2}\right)\end{array}$ & $\begin{array}{c}\text { Electrical } \\
\text { conductivity } \\
\text { (\% IACS) }\end{array}$ & $\begin{array}{c}\text { Unit cost } \\
(1000 \text { won } / \mathrm{Kg})\end{array}$ \\
\hline Ti-6Al-4V & 0.25 & $\begin{array}{l}\text { C } 0.08 \% \text {, Al 5.5 6.5\%, Ni 0.05\%, O 0.13\%, Ti } \\
88 \sim 90.08 \% \text {, V 3.5 4.5\%, Fe 0.25\%, H 0.013\% }\end{array}$ & 2005 & 1.01 & 1720 \\
\hline Phosphor bronze & 0.25 & P $0.03-0.35 \%$, Sn $4.5-9.0 \%$ & 2131 & 15 & 16 \\
\hline SS $304 \mathrm{Ni}$ & 0.2 & $\begin{array}{c}\text { C } 0.075 \% \text {, Si } 0.45 \% \text {, Mn } 1.25 \%, \text { P } 0.004 \% \text {, Ni } \\
8.47 \%\end{array}$ & 1685 & 25 & 22.5 \\
\hline SS 316 & 0.25 & $\begin{array}{c}\text { C below } 0.08 \% \text {, Si below } 1.0 \% \text {, Mn below } 2.0 \% \text {, } \\
\text { Cr } 16 \sim 18 \% \text {, Ni } 10 \sim 14 \% \text {, Mo } 2.0 \sim 3 \%\end{array}$ & 999 & 2.5 & 24.5 \\
\hline
\end{tabular}

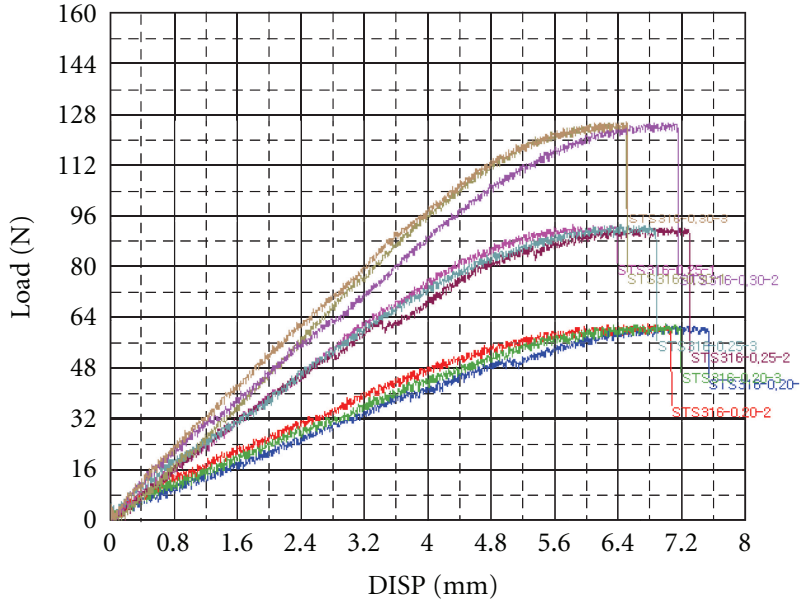

Figure 7: Tensile graph of SS $316(0.20,0.25,0.30 \mathrm{~mm})$; result of tensile strength was $183 \sim 210 \mathrm{kgf} / \mathrm{mm} 2$, which is superior to the range of tensile strength of currently used SS 304.

TABLE 4: Corrosion assessment of wire material in Hank's solution (x: corrosion was not observed. o: corrosion was observed).

\begin{tabular}{lcccc}
\hline $\begin{array}{l}\text { Diameter } \\
(\mathrm{mm})\end{array}$ & Ti-6Al-4V & $\begin{array}{c}\text { Phosphor } \\
\text { bronze }\end{array}$ & SS 304 Ni & SS 316 \\
\hline 0.2 & $\mathrm{x}$ & - & $\mathrm{o}$ & $\mathrm{x}$ \\
0.25 & - & $\mathrm{o}$ & $\mathrm{o}$ & $\mathrm{x}$ \\
0.3 & - & - & $\mathrm{o}$ & $\mathrm{x}$ \\
\hline
\end{tabular}

evaluated for travel speed and straightness with respect to thermal treatment conditions, and tensile strength was calculated with respect to the evaluated straight line. For the evaluation of straightness, the gap length was defined as the deviation from a reference line at a distance of $100 \mathrm{~mm}$, to measure the extent of bending. The tensile strength was calculated by dividing the maximum tensile load before material breakdown by that of an original cross-sectional area of the sample.

\section{Results}

3.1. Properties of Electroacupuncture Needle Materials. Ti$6 \mathrm{Al}-4 \mathrm{~V}$ is a $\mathrm{Ti}$ alloy with excellent biocompatibility that is used as a material for dental implants. Its electrical conductivity, however, is low, at 1.01\% (IACS - International Annealed Copper Standard), and it is also expensive. SS $304 \mathrm{Ni}$ is an existing SS 304 wire that is coated with $\mathrm{Ni}$, whose high electrical conductivity, at 25\% (IACS), improves the wire's conductivity. It is expected that this higher electrical conductivity can improve the effectiveness of electro acupuncture. SS 316 is the most commonly used stainless steel, along with SS 314. Compared to SS 314, SS 316 has a lower $\mathrm{Cr}$ - and a higher Ni-content, and Mo is added to it. It has a higher resistance to corrosion and creep but has inferior electrical conductivity, at 2.5\% (IACS), as compared to $3.0 \%$ for SS 304 (IACS) (Table 3).

\subsection{Biological Safety}

3.2.1. Corrosion Stability of Electroacupuncture Needle Material. The results of the corrosion stability tests of new acupuncture needle materials in simulated body fluid are as follows (Table 4). Examination with a stereoscopic microscope showed that there was no difference before and after electrical stimulus in Ti alloy (Figure 1). For PB, a stereoscopic microscope showed discoloring and SEM showed corrosion (Figure 2). SS $304 \mathrm{Ni}$ showed corrosion with both a stereoscopic microscope and SEM, for all thicknesses (Figure 3). SS 316 showed a corrosion-like appearance under a stereoscopic microscope, but no corrosion using SEM (Figure 4 and Table 4).

\subsubsection{MTT Assay}

(A) 5.1 Microplate Reader Absorbance Analysis (540 $\mu \mathrm{m}$ ). When cell viability was expressed as a percentage with respect to the negative control, $\mathrm{PB}$ showed the lowest viability $(50.5 \%)$ and SS $316(0.25 \mathrm{~mm})$ showed the highest viability (Table 5), (Figure 5).

Because there is no separate standard of cell viability for oriental medicine equipment, the standards of the Federation Dentaire Internationale (FDI) were used for our evaluation (Tables 6 and 7). In our results, Ti-6Al-4V, SS 316 , and SS $304 \mathrm{Ni}(0.25 \mathrm{~mm}$ and $0.3 \mathrm{~mm})$ showed mild cytotoxicity, while SS $304 \mathrm{Ni} 0.2 \mathrm{~mm}$ and phosphor bronze showed moderate cytotoxicity.

3.2.3. Stain Test Results. In the MTT assay, the degree of cell viability was high, except for PB and SS $304 \mathrm{Ni} 0.2 \mathrm{~mm}$, but 
TABLE 5: The absorbance $(540 \mathrm{~nm})$ from MTT assay and viability.

\begin{tabular}{|c|c|c|c|c|c|c|}
\hline & \multicolumn{4}{|c|}{ Absorbance } & \multirow[b]{2}{*}{ S.D. } & \multirow[b]{2}{*}{ Viability (average/control) } \\
\hline & 1 st & 2nd & 3rd & Average & & \\
\hline Ti-6Al-4V (0.20 mm) & 0.337 & 0.34 & 0.336 & 0.338 & 0.002 & $* 90.2 \%$ \\
\hline $\mathrm{PB}(0.25 \mathrm{~mm})$ & 0.188 & 0.189 & 0.191 & 0.189 & 0.002 & $* * * 50.58 \%$ \\
\hline SS $304 \mathrm{Ni}(0.20 \mathrm{~mm})$ & 0.289 & 0.295 & 0.29 & 0.291 & 0.003 & $* * 77.83 \%$ \\
\hline SS $304 \mathrm{Ni}(0.25 \mathrm{~mm})$ & 0.321 & 0.315 & 0.319 & 0.318 & 0.003 & $* * 85.049 \%$ \\
\hline SS $304 \mathrm{Ni}(0.30 \mathrm{~mm})$ & 0.304 & 0.306 & 0.304 & 0.305 & 0.001 & $* * 81.39 \%$ \\
\hline SS $316(0.20 \mathrm{~mm})$ & 0.362 & 0.361 & 0.355 & 0.36 & 0.004 & $95.99 \%$ \\
\hline SS $316(0.25 \mathrm{~mm})$ & 0.36 & 0.359 & 0.365 & 0.362 & 0.003 & $96.52 \%$ \\
\hline SS $316(0.30 \mathrm{~mm})$ & 0.358 & 0.357 & 0.362 & 0.359 & 0.003 & $95.9 \%$ \\
\hline Control & 0.376 & 0.374 & 0.373 & 0.374 & 0.002 & $100 \%$ \\
\hline
\end{tabular}

(*P $P 0.05,{ }^{* *} P<0.01,{ }^{* * *} P<0.001$ versus control).

TABle 6: Definition of index values.

\begin{tabular}{lc}
\hline 0 & No observable lysis \\
1 & Up to 20 percent \\
2 & $20-40$ percent \\
3 & $40-60$ percent \\
4 & $60-80$ percent \\
5 & Over 80 percent \\
\hline
\end{tabular}

TABLE 7: Response index and cytotoxicity.

\begin{tabular}{lc}
\hline Response index & Cytotoxicity \\
\hline 0 & None \\
1 & Mild \\
$2-3$ & Moderate \\
$4-5$ & Severe \\
\hline
\end{tabular}

TABLE 8: Results of safety and economic evaluation according to the material (x: corrosion was not observed. o: corrosion was observed).

\begin{tabular}{lccccc}
\hline Material & Thickness & Corrosion & $\begin{array}{c}\text { Viability } \\
\text { (MTT } \\
\text { assay) }\end{array}$ & $\begin{array}{c}\text { Viability } \\
\text { (stain } \\
\text { test) }\end{array}$ & $\begin{array}{c}\text { Cost } \\
\text { effectiveness }\end{array}$ \\
\hline $\begin{array}{l}\text { Ti-6Al- } \\
\text { 4V }\end{array}$ & $0.20 \mathrm{~mm}$ & $\mathrm{x}$ & $90.20 \%$ & High & Low \\
PB & $0.25 \mathrm{~mm}$ & o & $50.58 \%$ & Low & High \\
Ni co & $0.20 \mathrm{~mm}$ & o & $77.83 \%$ & Low & Normal \\
Ni co & $0.25 \mathrm{~mm}$ & o & $85.04 \%$ & Low & Normal \\
Ni co & $0.30 \mathrm{~mm}$ & o & $81.39 \%$ & Low & Normal \\
SS 316 & $0.20 \mathrm{~mm}$ & $\mathrm{x}$ & $95.99 \%$ & High & Normal \\
SS 316 & $0.25 \mathrm{~mm}$ & $\mathrm{x}$ & $96.52 \%$ & High & Normal \\
SS 316 & $0.30 \mathrm{~mm}$ & $\mathrm{x}$ & $95.90 \%$ & High & Normal \\
\hline
\end{tabular}

in the cell stain testing, PB and SS $314 \mathrm{Ni}$ for all thicknesses showed low cell viability compared to the control group (Figure 6(a)), except for Ti-6Al-4V (Figure 6(b)) and SS 316 (Figure 6(e1), 6(e2), 6(e3)).

3.3. Straightness and Tensile Strength. In our evaluation of corrosion, only Ti-6Al-4V and SS 316 were not corroded.
TABle 9: Process in accordance with the conditions of the wire straightness evaluation.

\begin{tabular}{|c|c|c|c|c|}
\hline Classification & $\begin{array}{c}\text { Temperature } \\
\left({ }^{\circ} \mathrm{C}\right)\end{array}$ & $\begin{array}{c}\text { Travel speed } \\
(\mathrm{m} / \mathrm{s})\end{array}$ & $\begin{array}{l}\text { Result } \\
(\mathrm{mm})\end{array}$ & Note \\
\hline 0.20 & 670 & 0.50 & 2.2 & Fail \\
\hline 0.20 & 670 & 0.58 & 2.4 & Fail \\
\hline 0.20 & 670 & 0.66 & 2.5 & Fail \\
\hline 0.20 & 700 & 0.50 & 1.2 & Pass \\
\hline 0.20 & 700 & 0.58 & 0.8 & Pass \\
\hline 0.20 & 700 & 0.66 & 1.0 & Pass \\
\hline 0.20 & 720 & 0.50 & 2.6 & Fail \\
\hline 0.20 & 720 & 0.58 & 2.4 & Fail \\
\hline 0.20 & 720 & 0.66 & 2.3 & Fail \\
\hline 0.25 & 670 & 0.50 & 2.0 & Pass \\
\hline 0.25 & 670 & 0.58 & 2.1 & Fail \\
\hline 0.25 & 670 & 0.66 & 2.3 & Fail \\
\hline 0.25 & 700 & 0.50 & 1.2 & Pass \\
\hline 0.25 & 700 & 0.58 & 1.0 & Pass \\
\hline 0.25 & 700 & 0.66 & 1.2 & Pass \\
\hline 0.25 & 720 & 0.50 & 2.0 & Pass \\
\hline 0.25 & 720 & 0.58 & 1.9 & Pass \\
\hline 0.25 & 720 & 0.66 & 1.6 & Pass \\
\hline 0.30 & 670 & 0.50 & 2.1 & Fail \\
\hline 0.30 & 670 & 0.58 & 2.3 & Fail \\
\hline 0.30 & 670 & 0.66 & 2.4 & Fail \\
\hline 0.30 & 700 & 0.50 & 1.7 & Pass \\
\hline 0.30 & 700 & 0.58 & 1.4 & Pass \\
\hline 0.30 & 700 & 0.66 & 1.5 & Pass \\
\hline 0.30 & 720 & 0.50 & 2.5 & Fail \\
\hline 0.30 & 720 & 0.58 & 2.2 & Fail \\
\hline 0.30 & 720 & 0.66 & 2.1 & Fail \\
\hline
\end{tabular}

In the MTT assay, Ti-6Al-4V, SS 316, and SS $314 \mathrm{Ni}$ showed excellent cell viability of grade 1 or higher. However, only Ti$6 \mathrm{Al}-4 \mathrm{~V}$ and SS 316 showed moderate cell viability in the stain test. In terms of cost, $\mathrm{Ti}$ alloy $(1720 \mathrm{KRW} / \mathrm{kg})$ is about 70 times more expensive than SS 316 (24.5 KRW/kg) (Table 8). 
TABLe 10: Result of tensile test.

\begin{tabular}{|c|c|c|c|c|c|c|}
\hline No. & Sample size & Sectional area & Maximum load & Tensile strength & Maximum displacement & Required time \\
\hline SS $316-0.20-1$ & 0.1997 & 0.03 & 6.28 & 209.333 & 7.540 & 00:00:45 \\
\hline SS $316-0.20-2$ & 0.1997 & 0.03 & 6.32 & 210.667 & 7.070 & 00:00:42 \\
\hline SS 316-0.20-3 & 0.1997 & 0.03 & 6.32 & 210.657 & 7.200 & 00:00:43 \\
\hline SS 316-0.25-1 & 0.248 & 0.05 & 9.54 & 190.880 & 6.390 & 00:00:38 \\
\hline SS 316-0.25-2 & 0.248 & 0.05 & 9.46 & 189.200 & 7.310 & $00: 00: 43$ \\
\hline SS 316-0.25-3 & 0.248 & 0.05 & 9.56 & 191.200 & 6.890 & 00:00:41 \\
\hline SS $316-0.30-1$ & 0.297 & 0.07 & 12.86 & 183.714 & 6.510 & 00:00:39 \\
\hline SS $316-0.30-2$ & 0.297 & 0.07 & 12.86 & 183.714 & 7.170 & 00:00:43 \\
\hline SS $316-0.30-3$ & 0.297 & 0.07 & 12.90 & 184.285 & 6.530 & 00:00:39 \\
\hline
\end{tabular}

In terms of electrical conductivity, the conductivity of Ti$6 \mathrm{Al}-4 \mathrm{~V}$ with $1.01 \%$ (IACS) was about 2.5 times lower than that of SS 316 with $2.5 \%$ (IACS). After consideration of the above results, SS 316 was selected as a candidate material for an electro acupuncture needle. After transforming the material into a needle shape, straightness and tensile strength tests were performed to check its conformity to standard specifications.

(1) Manufacture of Straight Wire. As a result of the linearization of SS 316 wire, wires with thicknesses of $0.20,0.25$, and $0.30 \mathrm{~mm}$ were all appropriate at a temperature condition of $700^{\circ} \mathrm{C} \pm 3^{\circ} \mathrm{C}$. The most appropriate straight product under $2.0 \mathrm{~mm}$ was obtained at a travel speed of $0.58 \mathrm{~m} / \mathrm{s} \pm 0.01 \mathrm{~m} / \mathrm{s}$ (Table 9).

(2) Evaluation of Straight Wire Tensile Strength. Measurements of the tensile strength of the qualified wire showed that the range of tensile strength was $183 \sim 210 \mathrm{kgf} / \mathrm{mm}^{2}$, which is superior to the range of tensile strength of currently used SS 304, which is $170 \sim 190 \mathrm{kgf} / \mathrm{mm}^{2}$ (Table 10, Figure 7).

\section{Discussion}

Electro acupuncture is a technique that applies an electrical stimulus to an inserted needle, and it is currently applied to a variety of illnesses in clinics worldwide [13]. However, the needles used in electro acupuncture, which correspond to electrodes for the low-frequency stimulation of meridian acupuncture points, are the same disposable needles that are used in conventional acupuncture. This has created a controversy regarding the corrosion of the needle in the course of the electrical stimulus treatment [5-7]. In order to resolve this controversy by discovering a new material that can replace the existing electrode and satisfy conditions for a disposable needle, for this study we selected 2 types of wires that have excellent electrical conductivity and 2 types of wires with a high degree of stability, both of which were commercially available. Phosphor bronze is a widely used contact terminal of the electronic device and known as a stable and a good conductor material. However, biological safety has not been confirmed. For this reason, we choose the material as a lowest reference of candidate. SS304 is conventional acupuncture needle material used in EA also. Ni-coated SS 304 was evaluated as composite material combined high conductive material with a conventional EA needle material, for batter electrical conductivity. Ti-6Al-4V is the most widely used titanium alloy in medical implant and known very safe. For this reason, we choose the material as a highest reference candidate. SS 316 has also been evaluated as a good candidate for the reason wide use in medical implant also, and other various invasive device material. A biocompatibility study, economic analysis, and corrosion testing after the application of electrical current showed that $\mathrm{PB}$ was unusable due to the severe cytotoxicity it displayed and that SS $304 \mathrm{Ni}$ was also unsuitable, as it showed low cell viability in stain testing and showed corrosion after the application of current. SS 316 and Ti alloy performed well in terms of cell viability and cytotoxicity and did not exhibit corrosion under $0.5 \mathrm{~mA}$ continuous wave, step response, $1 \mathrm{~ms}$ duration, and single-phase current for 60 minutes. The results of economic analysis and electrical conductivity testing showed that Ti-6Al-4V (1720 KRW/kg) is about 70 times more expensive than SS $316(24.5 \mathrm{KRW} / \mathrm{kg})$ and that the electrical conductivity of Ti-6Al-4V, at $1.01 \%$ (IACS), was about 2.5 times lower than that of SS 316, at $2.5 \%$ (IACS). In addition, even in biological safety SS 316 showed better results than Ti-6Al-4V. As a result, SS 316 was selected as a candidate material for an electro acupuncture needle and was then tested for straightness and tensile strength in order to confirm its successful transformation into needle form and its conformity to standard-KS, JIS and GB (Korea Standard- KS, Japanese Industrial Standard-JIS, Guojia Biaozhun/National Standard/China_-(GB) specifications. SS 316 satisfied straightness test under a condition of $0.58 \mathrm{~m} / \mathrm{s}$ $\pm 0.01 \mathrm{~m} / \mathrm{s}$, and its range of tensile strength was 183 $210 \mathrm{kgf} / \mathrm{mm}^{2}$, which is higher than the range of the currently used SS 304, which is $170 \sim 190 \mathrm{kgf} / \mathrm{mm}^{2}$. Based upon these overall results, it was confirmed that SS 316 is appropriate for use as a material for an acupuncture needle. This result is further supported by a report from Tang et al. [14] which states that SS 316 demonstrates superior resistance to electrochemical corrosion compared to SS 304 in both body fluid and cell growth environments. Clinical conditions, however, are much more complex than this, and a simple corrosion test in body fluid does not constitute a guarantee of safety. Therefore, wide-ranging research on the safety of an 
SS 316 needle with applied current under various conditions must be performed, and, based upon such researches, guidelines for safe usage should be developed for different treatment conditions.

\section{Conclusion}

In order to develop new material for an acupuncture needle that is safe for electrical current stimulus, 4 types of commercially available materials were tested for their biological safety and risk of corrosion caused by applied current. Based upon our results, the following conclusions were reached.

(1) SS 316 showed best biological safety and cost effectiveness as an electro acupuncture needle material.

(2) Testing for straightness and tensile strength of SS 316 showed that it is suitable as an acupuncture needle under the condition of $0.58 \mathrm{~m} / \mathrm{s} \pm 0.01 \mathrm{~m} / \mathrm{s}$.

In summary, it was confirmed that a disposable needle capable of transmitting electrical stimulus can be manufactured using SS 316. If an animal study using an SS 316 needle is performed in the future to study the degree of corrosion under various electrical stimulus conditions and to research the materials capacity to provide safe treatment, this will facilitate the development of safer and more effective acupuncture treatment.

\section{Acknowledgments}

This work was supported by a grant from the Korea Institute of Oriental Medicine for the development of disposable and sterile needles for electro acupuncture (C11020) and Developement of Acupuncture, Moxibustion and Meridian Standard Health Technology (K11010).

\section{References}

[1] J. G. Kim, S. I. Kang, H. S. Kim et al., The Theory and Procedure of Electroacupuncture, Seowondang, Seoul, Korea, 1993.

[2] H. R. Liu, X. M. Wang, E. H. Zhou et al., "Acupuncture at both ST25 and ST37 improves the pain threshold of chronic visceral hypersensitivity rats," Neurochemical Research, vol. 34, no. 11, pp. 1914-1918, 2009.

[3] H. Ouyang, J. Yin, Z. Wang, P. J. Pasricha, and J. D. Z. Chen, "Electroacupuncture accelerates gastric emptying in association with changes in vagal activity," American Journal of Physiology, vol. 282, no. 2, pp. G390-G396, 2002.

[4] M. T. Cabioğlu and N. Ergene, "Electroacupuncture therapy for weight loss reduces serum total cholesterol, triglycerides, and ldl cholesterol levels in obese women," The American Journal of Chinese Medicine, vol. 33, no. 4, pp. 525-533, 2005.

[5] C. D. Lytle, B. M. Thomas, E. A. Gordon, and V. Krauthamer, "Electrostimulators for acupuncture: safety issues," Journal of Alternative and Complementary Medicine, vol. 6, no. 1, pp. 3744, 2000.

[6] M. Cummings, "Safety aspects of electroacupuncture," Acupuncture in Medicine, vol. 29, no. 2, pp. 83-85, 2011.
[7] K.M. Park, Assessment of acupuncture needle stability and safety in applying electroacupuncture, M.S. thesis, Kyungwon University, 2009.

[8] S. S. Jin, Study of mechanical stability and safety of electroacupuncture on localized fat deposit, Ph.D. thesis, Kyungwon University, 2008.

[9] H.S. Hwang, S.T. Koo, Y.H. Ryu et al., "Electric corrosion of STS304 acupuncture needles used for electroacupuncture," The Journal of Korean Acupuncture \& Meridian, vol. 24, no. 5, pp. 105-111, 2007.

[10] S. K. Choi, Y. J. Song, and Y. S. Kim, "Influence of corrosion condition and alloying elements on the corrosion resistance of stainless steels," Bulletin of Industrial Technology Research Institute, Andong Nat'l University, vol. 3, no. 1, pp. 31-38, 1996.

[11] U. J. Lim, K. C. Jung, and S. Y. Lee, The Corrosion and Prevention of Machined Materials, Hyungseul, Seoul, Korea, 2006.

[12] S. H. Lee, S. B. Lee, K. H. Choi, and Y. H. Ryu, "Over time stability of ear acupuncture needle in body fluid," The Journal of Korean Acupuncture \& Moxibustion Society, vol. 28, no. 5, pp. 97-102, 2011.

[13] Y. T. Choi, Acupuncture and Moxibustion, Jipmundang, Seoul, Korea, 2001.

[14] Y. C. Tang, S. Katsuma, S. Fujimoto, and S. Hiromoto, "Electrochemical study of type 304 and 316L stainless steels in simulated body fluids and cell cultures," Acta Biomaterialia, vol. 2, no. 6, pp. 709-715, 2006. 


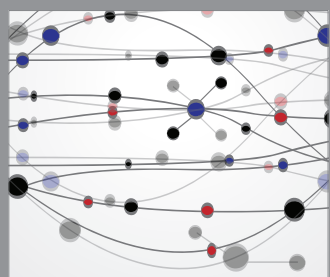

The Scientific World Journal
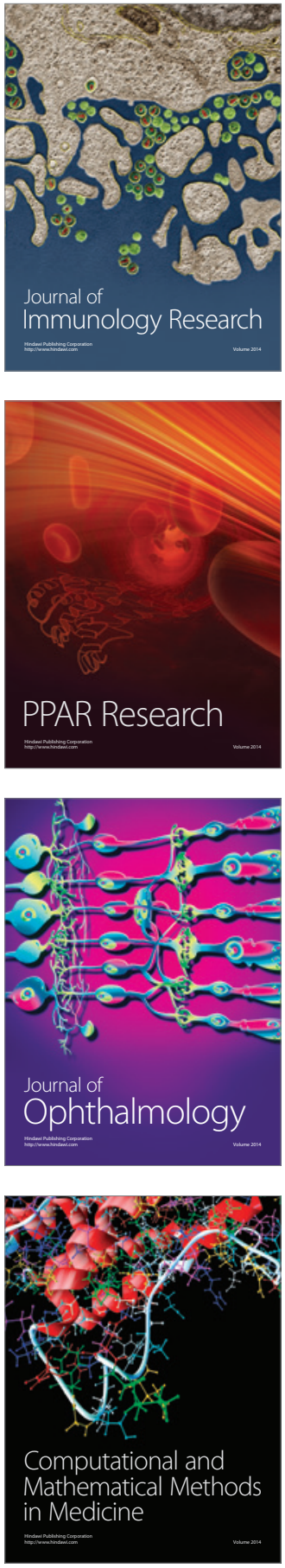

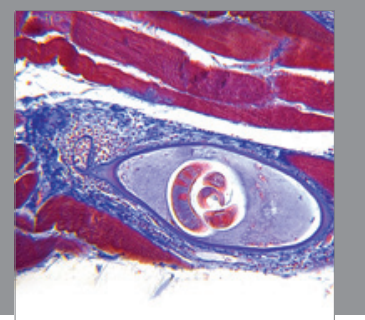

Gastroenterology

Research and Practice
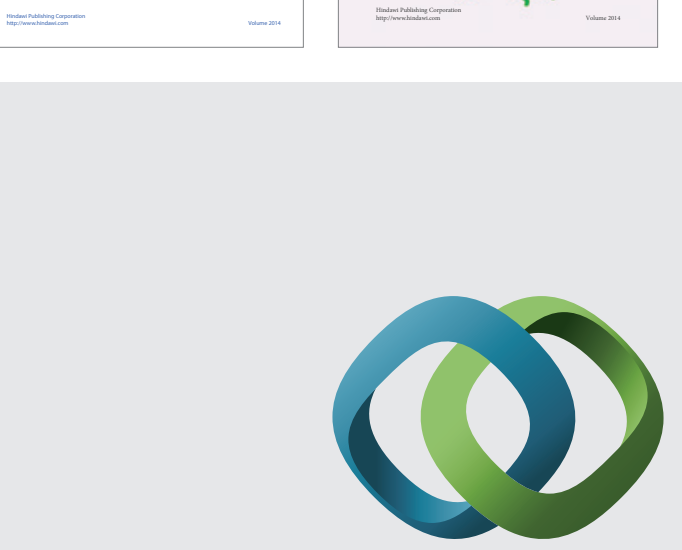

\section{Hindawi}

Submit your manuscripts at

http://www.hindawi.com
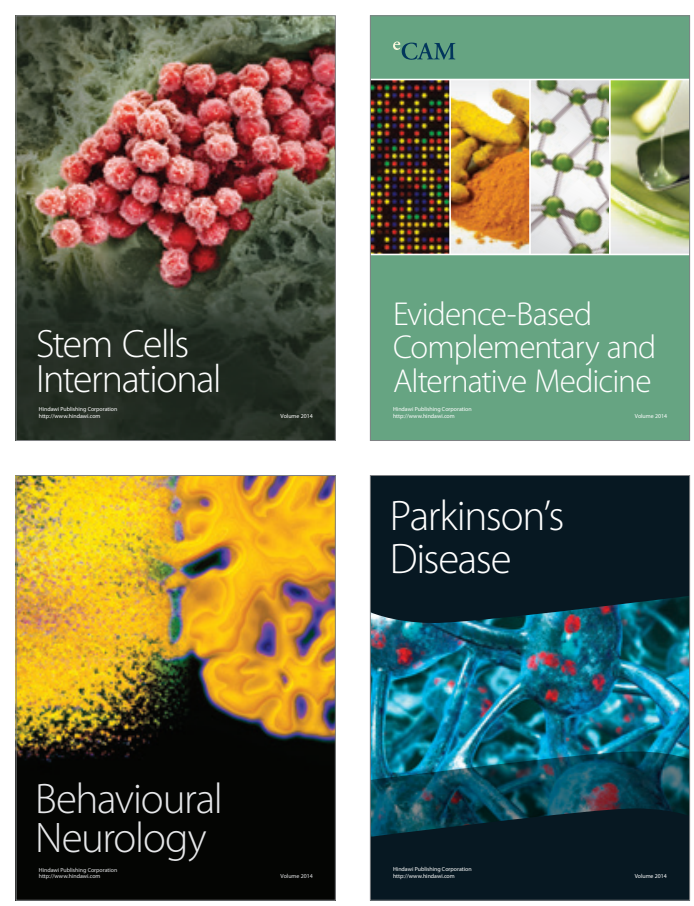

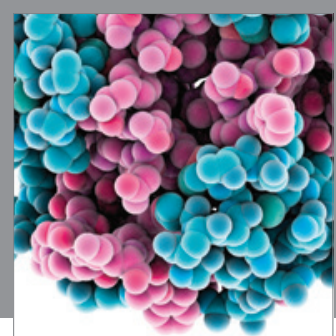

Journal of
Diabetes Research

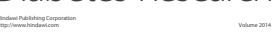

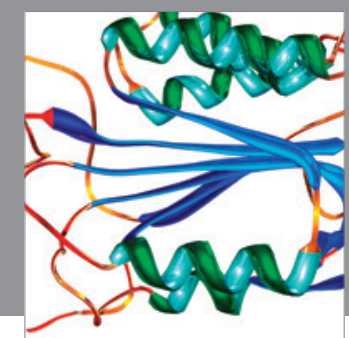

Disease Markers
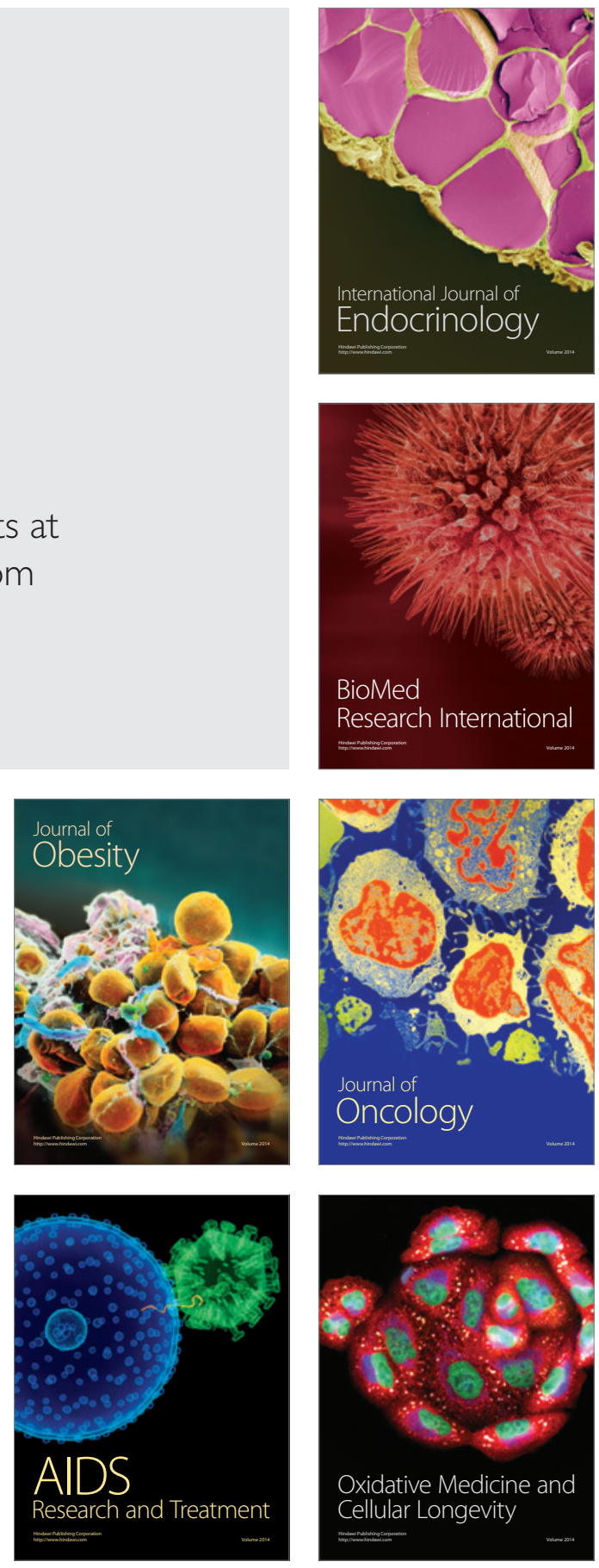